\title{
Postharvest Leaf Blackening and Preharvest Carbohydrate Status in Three Protea Species
}

\author{
Robyn McConchie ${ }^{1}$ and N. Suzanne Lang ${ }^{2}$ \\ Department of Horticulture, Julian C. Miller Hall, Louisiana Agricultural \\ Experiment Station, Louisiana State University Agricultural Center, Baton \\ Rouge, LA 70803
}

Additional index words. cut flowers, source-sink

\begin{abstract}
Protea neriifolia R. Br., P. susannae E.P. Phillips $\times$ compacta R. Br., and $P$. eximia (Salis. ex Knight) Fourcade cut flower stems were examined to determine the relationship between postharvest leaf blackening rate and preharvest carbohydrate status. Postharvest leaf blackening was highest $(83 \%$ by day 4$)$ in $P$. eximia floral stems, which had the lowest preharvest sucrose concentrations. In contrast, $P$. susannae $\times$ compacta had $<5 \%$ leaf blackening by day 4 and the highest preharvest leaf sucrose concentrations. Starch concentrations were highest in $\boldsymbol{P}$. neriifolia; however, leaf blackening was intermediate between $P$. susannae $\times$ compacta and $P$. eximia and reached $52 \%$ at day 4 . Preharvest carbon-exchange rate and stomata1 conductance in all three species were extremely low, despite high photosynthetically active radiation and apparent lack of water stress. Comparing preharvest carbohydrate profiles in vegetative and floral stems suggests that vegetative stems may have a sink-to-source transition zone between the second and third divisions, while most leaves on floral stems may have transferred carbohydates to source leaves at harvest. While preharvest floral stem sucrose concentrations can be linked to leaf blackening rate, the high starch reserves in $P$. neriifolia reduced leaf blackening little in this species. We conclude that leaf blackening may be related more to inflorescence sink demand after harvest and oxidative substrate availability than preharvest reserve carbohydrate concentrations in each species.
\end{abstract}

Premature leaf blackening on many cutflower Protea species during postharvest holding seriously reduces vase life and market value. Blackening symptoms usually appear 3 to 7 days after harvest when stems are kept in darkness. Leaf blackening in $P$. neriifolia (PN) (McConchie et al., 1991) and $P$. eximia (PE) (Bieleski et al., 1992) has been attributed to carbohydrate depletion in leaves. During the postharvest period, nonstructural carbohydrates are translocated from leaves to the floral sink to continue floral development. McConchie and Lang (1993) have demonstrated that, under standard shipping conditions, up to $82 \%$ of starch reserves is depleted from PN leaves within $24 \mathrm{~h}$ of harvest. However, stems with delayed leaf blackening maintain higher carbohydrate concentrations in the initial postharvest period. In contrast, early leaf blackening in floral stems is preceded by rapid leaf carbohydrate depletion (McConchie and Lang, 1993).

\footnotetext{
Received for publication 23 July 1992. Accepted for publication 3 Dec. 1992. Journal Series paper no. 92-28-6244, Louisiana Agricultural Experiment Station, Louisiana State Univ. Agricultural Center. We thank G. McClure for valuable technical assistance and J. and M. Nelson, Goleta, Calif., for donating flowers. The cost of publishing this paper was defrayed in part by the payment of page charges. Under postal regulations, this paper therefore must be hereby marked advertisement solely to indicate this fact.

'Graduate Research Assistant.

${ }^{2}$ Assistant Professor.
}

liter deionized distilled water containing 50 ppm hypochlorite. Stems were kept in darkness for $24 \mathrm{~h}$ at $25 \mathrm{C}( \pm 1 \mathrm{C})$ in a growth chamber (Environmental Growth Chambers, Chagrin Falls, Ohio). The number of leaves per stem with $\geq 10 \%$ blackened surface area was recorded daily for 11 days. Blackening was expressed as a percentage of the total number of leaves per stem.

\section{Physiological studies}

Field-grown plants. Based on uniformity, one vegetative and one floral stem (at soft-tip maturity) were selected on three plants of each species noted growing at the same commercial plantation described above. Seven phyllotactic divisions (one division equals one complete leaf spiral) were tagged on each stem beginning at the apex. Carbon-exchange rate (CER) and stomatal conductance were measured for each division, as described by McConchie et al. (1991), under ambient photosynthetically active radiation (PAR) (1500 to $\left.1975 \mu \mathrm{mol} \cdot \mathrm{m}^{-2} \cdot \mathrm{s}^{-1}\right)$ between 1030 and 1330 HR. Four leaf disks $(0.5 \mathrm{~cm}$ in diameter $)$ were removed from two leaves in each phyllotactic division, frozen at $-80 \mathrm{C}$, and lyophilized for carbohydrate analysis (McConchie et al., 1991). Soluble carbohydrates were extracted and quantified using high-performance liquid chromatography as described by McConchie and Lang (1993). Starch concentrations were determined using the method of Robbins and Pharr (1988).

Glasshouse-grown plants. Based on uniformity, three vegetative stems were selected on each of six well-watered glasshouse-grown PS plants, and the third and sixth phyllotactic divisions were tagged and measured for photosynthetic rate and stomatal conductance during a 16-h interval that began before dawn and ended after sunset. Three plants were placed in a growth chamber (Environmental Growth Chambers, Chagrin Falls, Ohio) and kept at $25 \mathrm{C}( \pm 1 \mathrm{C})$ under $12 \mathrm{~h}$ of light each 24 $\mathrm{h}$ from 0730 to $1930 \mathrm{HR}$. The remaining three plants were placed outside under ambient temperature and PAR. Measurements were taken every $2 \mathrm{~h}$ from 0530 to $2130 \mathrm{HR}$; each data point represents an average of measurements from the third and sixth phyllotactic divisions. PAR and temperature were monitored and recorded during CER measurement.

Statistical analysis. The postharvest leaf blackening data set was analyzed as a repeated-measures design with a one-way treatment structure (three plant species, 11 days, $n$ =6) (Milliken and Johnson, 1984). The preharvest data sets were analyzed as completely randomized designs with two-way treatment structures (three plant species, seven phyllotactic divisions, $n=3$ ). Means were separated using Duncan's new multiple range test. All analyses were performed using the SAS statistical package (SAS, 1987).

Due to the extremely low CER and degree of stomatal closure in PS and PE, these characteristics could not be measured on three replicate stems in the allotted time. Therefore, CER and stomatal conductance data presented 
for these two species represent an average of the seven phyllotactic divisions of one floral and one vegetative stem.

Leaf blackening. Leaf blackening development was significantly different $(P=0.003)$ in the three species examined (Fig. 1). PS leaf blackening was significantly less $(P<0.05)$ than that of PN or PE. PS had $<5 \%$ leaf blackening by day 4 . In contrast, PE leaf blackening developed rapidly, rising from $17 \%$ to $83 \%$ between days 3 and 4 and reaching $100 \%$ by day 5 . Leaf blackening was intermediate in PN, reaching 52\% on day 4. All three species developed $\approx 100 \%$ leaf blackening by day 9.

CER and stomatal conductance. In fieldgrown plants of all three species, CER and stomatal conductance were low and did not vary significantly between floral and vegetative stems or across the seven phyllotactic divisions. PN CER averaged 1.13 and $0.93 \mathrm{mg}$ $\mathrm{CH}_{2} \mathrm{O} / \mathrm{dm}^{2}$ per hand stomatal conductance averaged 0.27 and $0.30 \mathrm{~mol} \cdot \mathrm{m}^{-2} \cdot \mathrm{s}^{-1}$ for floral and vegetative stems, respectively. PS CER in floral and vegetative stems averaged 0.09 and $0.11 \mathrm{mg} \mathrm{CH} \mathrm{CH}_{2} / \mathrm{dm}^{2}$ per $\mathrm{h}$ and stomatal conductance averaged 0.07 and $0.06 \mathrm{~mol} \cdot \mathrm{m}^{-2} \cdot \mathrm{s}^{-1}$, respectively. PE CER averaged 0.07 and 0.02 $\mathrm{mg} \mathrm{CH}_{2} \mathrm{O} / \mathrm{dm}^{2}$ per $\mathrm{h}$, and stomatal conductance averaged 0.02 and $0.05 \mathrm{~mol} \cdot \mathrm{m}^{-2} \cdot \mathrm{s}^{-1}$ for floral and vegetative stems, respectively. The low stomatal conductance measured in PS and PE probably was due to the virtual cessation of carbon fixation in these two species.

The low CER in PN was similar to that measured previously for cut stems of this species in a growth chamber under low PAR $\left(120 \mu \mathrm{mol} \cdot \mathrm{m}^{-2} \cdot \mathrm{s}^{-1}\right)$ (McConchie et al., 1991). It is particularly striking that CER was even lower $(\approx 10 x)$ in PS and PE. Water stress probably did not cause low stomatal conductance and CER in this experiment, since soil tensiometer readings (38 $\mathrm{kPa}$ at $30 \mathrm{~cm}$ deep) indicated that there was an adequate water supply. Further, plants did not have any visual symptoms of stress. The evolution of these Protea species under xerophytic environmental conditions may have resulted in consistently low carbon-fixation rates or alternative carbonfixing mechanisms. CER in other xerophytic woody plantspecies such as Nerium oleander

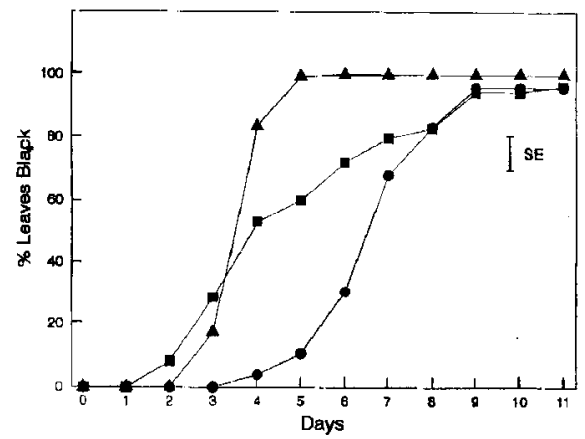

Fig. 1. Percentage of leaves with $\geq 10 \%$ area blackened on floral stems at $25 \mathrm{C}( \pm 1 \mathrm{C})$ in the dark. Species were (ם) Protea neriifolia, (O) $P$. susannae $\mathrm{X}$ comparta, and (A) P. eximia. Bars indicate the maximum SE associated with least square means $(n=6)$.
L. and Eucalyptus spp. ranges from $\approx 10$ to 25 $\mu \mathrm{mol} \cdot \mathrm{m}^{-2} \cdot \mathrm{s}^{-1}$ (25C) (Ferrar et al., 1989). Additionally, many evergreen shrubs adapted to desert environments have relatively low $(\approx 11$ $\mu \mathrm{mol} \cdot \mathrm{m}^{-2} \cdot \mathrm{s}^{-1}$ ) photosynthetic capacities (Smith and Nobel, 1986). CER measured in the three Protea species in this study was below these levels- 0.22 to $10.52 \mu \mathrm{mol} \cdot \mathrm{m}^{-2} \cdot \mathrm{s}^{-1}$.

The low CER and stomatal conductance measured in field-grown PS plants were confirmed later by measuring the same photosynthetic characteristics in vegetative glasshousegrown PS plants (Fig. 2). Under ambient and growth-chamber PAR $(\approx 800$ and 100 $\mu \mathrm{mol} \cdot \mathrm{m}^{-2} \cdot \mathrm{s}^{-1}$, respectively) (Fig. $2 \mathrm{~A}$ ), photosynthesis rates were $<3 \mu \mathrm{mol} \cdot \mathrm{m}^{-2} \cdot \mathrm{s}^{-1}$ (Fig. 2C). Stomatal conductance was also low and comparable to that measured in the field-grown plants (Fig. 2D). Stomatal conductance began to increase at dusk (1930 HR) in the ambientheld plants and at the end of the photoperiod (1930 HR) for the growth-chamber-held plants. Unlike $\mathrm{C}_{3}$ plants, arid environment-adapted plants using the Crassulacean acid metabolism (CAM) carbon-fixation mode typically open stomates at night to fix carbon into malic acid, which is decarboxylated during the day while stomates are closed to conserve water (Osmond, 1976). The data therefore suggest that PS plants may use the CAM or facultative CAM carbon-fixation mode. This characteristic would account for the low CER observed. Further inquiry into Protea carbon-fixing mechanisms is warranted.

Carbohydrate status. The major nonstructural carbohydrates found in floral and vegetative stems of all three species were starch, sucrose, and the sugar alcohol 1,5-anhydro-Dglucitol (polygalatol). Fructose, glucose, and maltose were detected in the soluble carbohydrate fraction at $<1.9 \mathrm{mg} \cdot \mathrm{dm}^{-2}$ and are not reported.

Leaf starch concentrations were similar for floral (Fig. 3A) and vegetative stems (Fig. 3B) for each species. However, starch concentrations in PN leaves were significantly higher $(P$

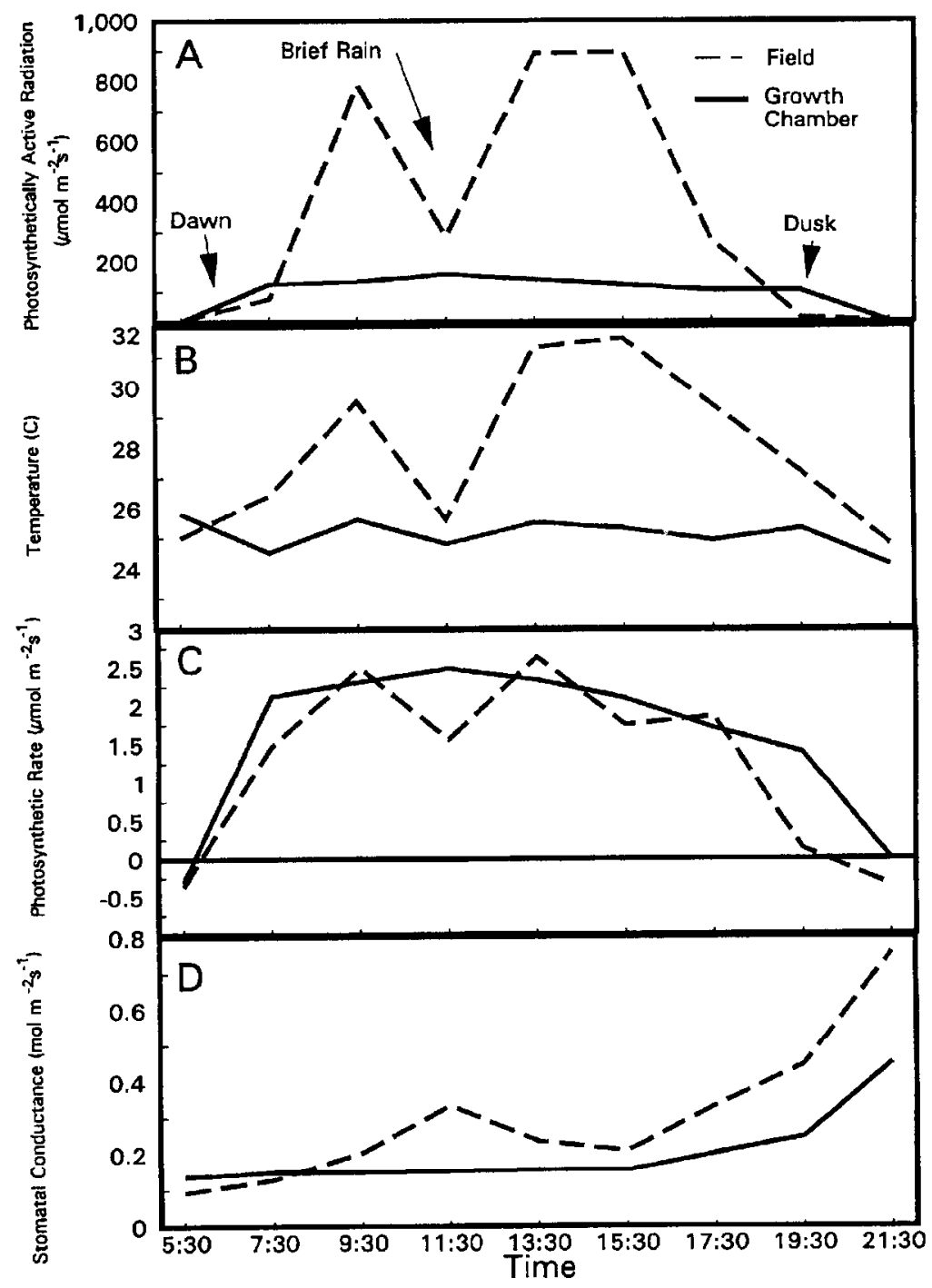

Fig. 2. Changes in average leaf photosynthetically active radiation (PAR), temperature, rate of photosynthesis, and stomatal conductance measured at the third and sixth phyllotactic divisions on vegetative glasshouse-grown Protea susannae $\mathrm{x}$ compacta plants placed in a growth chamber $(25 \pm 1 \mathrm{C}, \approx 100$ $\left.\mu \mathrm{mol} \cdot \mathrm{m}^{-2} \cdot \mathrm{s}^{-1}\right)$ under $12 \mathrm{~h}(0730-1930 \mathrm{HR})$ light each $24 \mathrm{~h} \mathrm{(一),} \mathrm{or} \mathrm{outside} \mathrm{under} \mathrm{ambient} \mathrm{PAR} \mathrm{(dawn} \mathrm{=}$ $0600 \mathrm{HR}$, dusk $=1930 \mathrm{HR}$ ) and temperature (---). 
$<0.05)$ for both stem types than in leaves of the other species. Starch concentrations in PS and PE floral and vegetative stems did not differ significantly across all seven phyllotactic divisions (Fig. 3A and B). Starch concentrations for vegetative stems in all three species were lower in the first two than in higher phyllotactic divisions (Fig. 3B). A similar starch pattern existed in floral stems, except for PS, which had the highest starch concentration at the first division (Fig. 3A).

Floral stem leaf sucrose concentrations were significantly different $(P=0.0001)$ among the three species; PS had the highest and PE the lowest concentration (Fig. 4A). On floral stems, phyllotactic division did not influence sucrose concentration significantly; this result suggests that leaves subtending the inflorescence may be source leaves. In contrast, phyllotactic division significantly influenced sucrose concentration $(P=0.0001)$ in vegetative stems of the three species (Fig. 4B). Sucrose concentrations were lowest in the first two divisions and increased basipetally. Older PE leaves (2 fourth
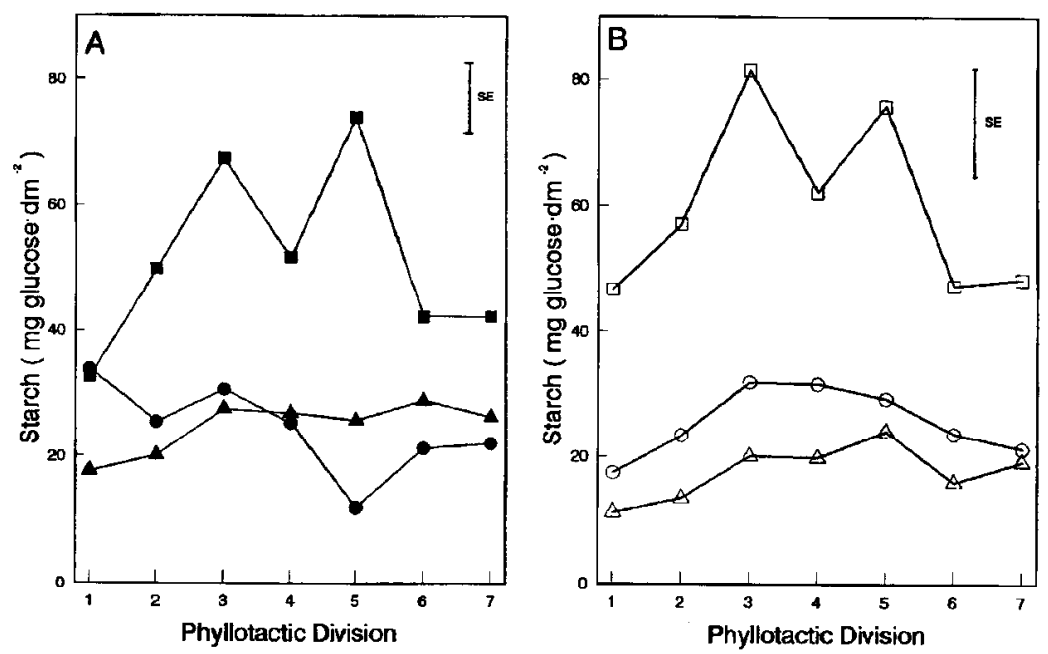

Fig. 3. Changes in preharvest leaf starch concentrations across phyllotactic division of (A) floral and $(\mathbf{B})$ vegetative stems in $(\square)$ Protea neriifolia, $(\mathbf{O})$ P. susannae $\times$ compacta, and $(\mathbf{A})$ P. eximia. Bars indicate the maximum SE associated with least square means $(n=3)$.
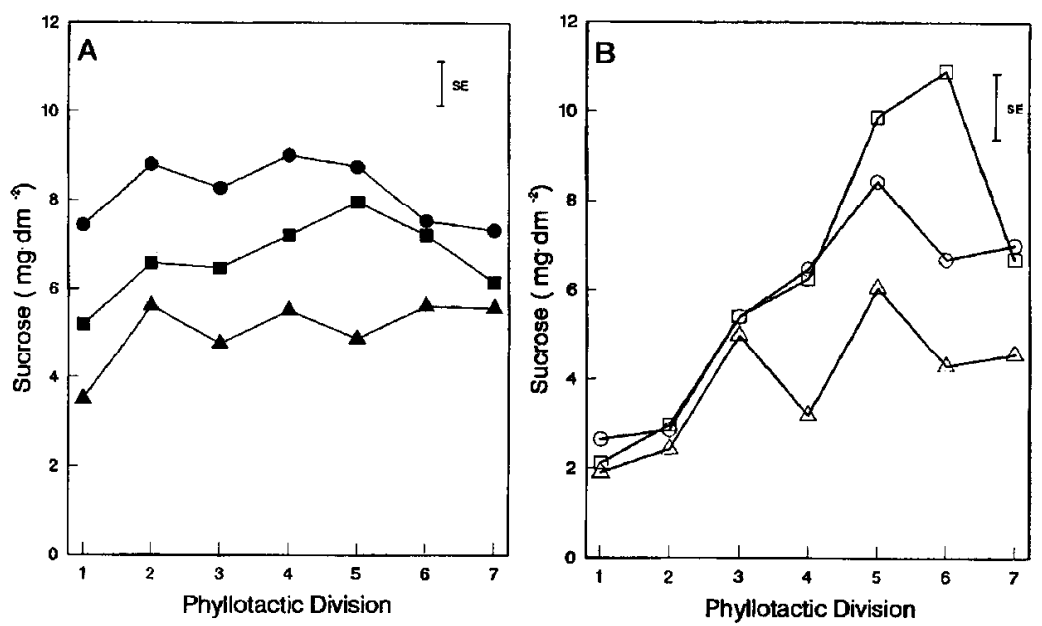

Fig. 4. Changes in preharvest leaf sucrose concentrations across phyllotactic division of (A) floral and (B) vegetative stems in $(\square)$ Protea neriifolia, $(\mathbf{O})$ P. susannae $X$ compacta, and $(\mathbf{\Lambda})$ P. eximia. Bars indicate the maximum SE associated with least square means $(n=3)$. sition zone. Developing leaves can be classified as utilization sinks, where imported carbohydrates are used for respiration and growth, rather than storage (Ho, 1988). Thus, low starch concentrations in leaves at the first division may indicate heterotrophic status. Starch metabolism in source leaves, however, is linked closely to photosynthetic capacity and sink requirements, which may vary diurnally (Beck and Ziegler, 1989). A phyllotactic starch pattern similar to that of stems in this study was found on intact vegetative stems of glasshouse-grown PS plants (McConchie et al., 1991); however, starch concentration rose sharply at the fifth division. The differences in transition zone between field-grown and glasshouse-grown plants may vary based on environmental influences to which field-grown plants are subjected and the resulting growth cycle. Consequently, a more active growth cycle may result in a more basipetal transition zone.

Of particular interest is the difference in carbohydrate patterns between floral and vegetative stems. Unlike vegetative stems, the similarity of sucrose profiles across floral stem phyllotactic divisions (Fig. 4A) suggests that, after flower initiation and during inflorescence, most leaves may be source leaves by the time floral stems are harvested. Additionally, floral stem sucrose concentrations at the first and second divisions are two to three times higher than comparable divisions in vegetative stems (Fig. 4 A and B). The high starch concentration at the first division in PS (Fig. 3A) further supports the hypothesis that floral stem leaves may be source leaves. However, low starch concentrations at the first division in PN and PE suggests that the most acroptal leaves still may be undergoing transition from sink to source status. The time between flower initiation and anthesis for some members of the Proteaceae, such as Banksia spp., can be several months (Fuss et al., 1992). Since similar periods have been observed for floral development in the three Protea spp. in this study, transition of most subtending leaves to source-leaf status would not be unexpected.

Floral stem leaf polygalatol concentrations did not differ significantly $(P=0.06)$ between species (Fig. 5A); however, vegetative stem concentrations were highest $(P<0.05)$ in PS (Fig. 5B). Floral and vegetative stem leaf polygalatol concentrations declined significantly $(P=0.009$ and 0.0001 , respectively) in a basipetal pattern. Thus, leaves closest to the apex consistently had the highest concentration of polygalatol, irrespective of species. Some sugar alcohols, such as sorbitol, are primarily transport carbohydrates and accumulate in source tissue where they are synthesized (Merlo and Passera, 1991). However, osmoregulation also has been hypothesized as an alternate role for sugar alcohols (Bieleski, 1982). Cheeseman (1988) suggested that such compounds used by the plant for osmotic adjustment in dry or saline habitats usually are not available for growth. Recent studies have shown that leaf polygalatol concentrations in PN and PE do not decrease under carbohydrate stress during postharvest holding 

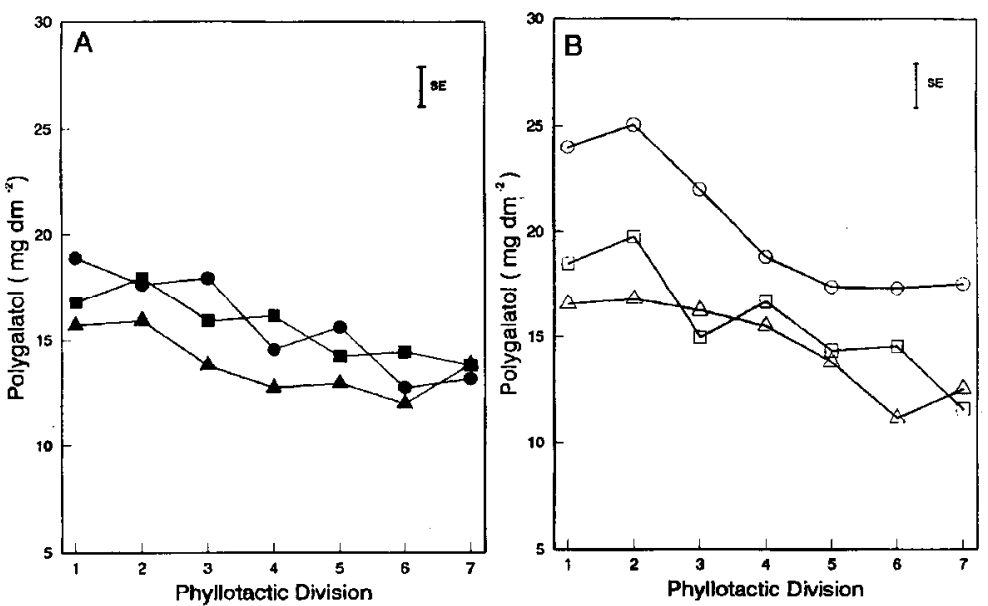

Fig. 5. Changes in preharvest leaf polygalatol concentrations across phyllotactic division of (A) floral and $(\mathbf{B})$ vegetative stems in $(\boldsymbol{\square})$ Protea nerifolia, $(\mathbf{O}) P$. susannae $\times$ compacta, and $(\boldsymbol{\Lambda}) P$. eximia. Bars indicate the maximum SE associated with least square means $(n=3)$.

(Bieleski et al., 1992; McConchie and Lang, 1993). Thus, a higher polygalatol concentration in the most acropetal leaves, coupled with its apparent unavailability for transport postharvest, suggests that polygalatol plays a role in osmotic adjustment in Protea spp.

Comparing preharvest carbohydrate profiles of the three species examined did not demonstrate a clear relationship between leaf blackening rate and preharvest reserve carbohydrate concentrations. Despite substantially higher starch levels in PN leaves (Fig. 3A), leaf blackening developed faster than in PS, which had lower starch reserves. Sucrose concentrations, however, are related more closely to differences in leaf blackening rate (Figs. 1 and 4A). Highest leaf sucrose concentrations were found in PS, which had a slower leaf blackening rate than the other two species. Further, PE had the lowest sucrose concentrations and developed leaf blackening symptoms most rapidly. Under high sink demand, starch reserves are metabolized to transport sucrose. Floral PN stems had about twice the leaf starch concentration of PS stems (Fig. $3 \mathrm{~A})$. This concentration, when combined with sucrose concentrations (Fig. 4A), represents a higher overall carbohydrate status. Collectively, these data suggest that leaf blackening rate may be related more to postharvest inflorescence sink demand than to total preharvest carbohydrate reserves. Sink strength of PN inflorescence seems to be substantial, since up to $82 \%$ of starch is depleted from leaves during the first $24 \mathrm{~h}$ after harvest (McConchie and Lang, 1993). Therefore, leaf blackening may be induced by the substantial carbohydrate depletion that occurs during continued darkness associated with shipping, irrespective of carbohydrate concentration in the leaves at harvest. Selecting Protea species and cultivars less prone to leaf blackening and using postharvest treatments that supply sufficient carbohydrate substrate to the cut flower stem remain the most effective means of preventing leaf blackening.
Whitehead and de Swardt (1982) hypothesized that leaf blackening symptoms are caused by the oxidation of polyphenols and leuco-anthocyanins by the enzymes polyphenol oxidase and peroxidase under carbohydrate depletion. Susceptibility to leaf blackening, in conjunction with depleting carbohydrate reserves, may be related more to enzyme activity and their substrate concentrations in the three species examined than preharvest carbohydrate concentrations. Protea species contain high concentrations of phenolic glycosides (Perold et al., 1979), which, under low carbohydrate status, may be hydrolyzed to release free phenols for oxidation and glucose for metabolism (Dey and Dixon, 1985). Thus, the reduction in leafblackening achieved when cut stems are placed under lighted postharvest conditions (Bieleski et al., 1992, McConchie et al., 1991) or treated with a 24-h 20\% sucrose pulse (Jones, 1991; McConchie and Lang, 1993) may increase carbohydrate substrates and allow floral development to continue and side cleavage. Additionally, further investigation into carbon-fixation mechanisms in Protea spp. may contribute to understanding the physiological mechanisms resulting in leaf blackening.

\section{Literature Cited}

Beck, E. and P. Ziegler. 1989. Biosynthesis and degradation of starch in higher plants. Annu. Rev. Plant Physiol. Plant Mol. Biol. 40:95-117.

Bieleski, R.L. 1982. Sugar alcohols, p. 158-192. In: F.A. Loewus and W. Turner (eds.). Plant carbohydrates. I. Intracellular carbohydrates. Encyclopedia of plant physiology new series. vol. 13A. Springer-Verlag, New York.

Bieleski, R.L., J. Ripperda, J.P. Newman, and M.S. Reid. 1992. Carbohydrate changes and leaf blackening in cut flower stems of Protea eximia. J. Amer. Soc. Hort. Sci. 117:124-127.

Cheeseman, J.M. 1988. Mechanism of salinity tolerance in plants. Plant Physiol. 87:547-550.

Dey, P.M. and R.A. Dixon. 1985. Glycosides, p. 131-148. In: P.M. Dey and R.A. Dixon (eds.). decrease the requirement for phenolic glyco-
Biochemistry of storage carbohydrates in green plants. Academic, New York.

Ferrar, P.J., R.O. Slatyer, and J.A. Vranjic. 1989. Photosynthetic temperature acclimation in $\mathrm{Eu}$ calyptus species from diverse habitats, and a comparison with Neruim oleander. Aust. J. Plant Physiol. 16:199-217.

Fuss, A.M., S.J. Pattison, D. Aspinall, and M. Sedgley. 1992. Shoot growth in relation to cut flower production of Banksia coccinea and Banksia menziesii (Proteaceae). Scientia Hort. 49:323-334.

Giaquinta, R.T. 1980. Translocation of sucrose and oligosaccharides, p. 27 1-320. In: J. Preiss (ed.). The biochemistry of plants. vol. 3. Carbohydrates: Structure and function. Academic, New York.

Ho, L.C. 1988. Metabolism and compartmentation of imported sugars in sink organs in relation to sink strength. Annu. Rev. Plant Physiol. Plant Mol. Biol. 39:355-378.

Jones, R.B. 1991. Understanding and controlling leaf blackening in Protea leaves: The use of high concentrations of sucrose. Proc. Intl. Protea Assn. Proc. 6th Biennial Conf. Perth, W.A. Australia. 22-27 Sept. p. 313-322.

McConchie, R. and N.S. Lang. 1993. Carbohydrate metabolism and possible mechanisms of leaf blackening in Protea neriifolia under dark postharvest conditions. J. Amer. Soc. Hort. Sci. 118. (In press.)

McConchie, R., N.S. Lang, and KC. Gross. 1991. Carbohydrate depletion and leaf blackening in Protea neriifolia. J. Amer. Soc. Hort. Sci. 116:1019-1024.

Merlo, L. and C. Passera. 1991. Changes in carbohydrate and enzyme levels during development of leaves of Prunus persica, a sorbitol synthesizing species. Physiol. Plant. 83:621-626.

Milliken, G.A. and D.E. Johnson. 1984. Analysis of messy data. vol. 1. Designed experiments. Van Nostrand Reinhold, New York. p. 323-350.

Newman, J.P., W. vanDoorn, and M.S. Reid. 1989. Carbohydrate stress causes leaf blackening. J. Intl. Protea Assn. 18:44-46.

Osmond, C.B. 1976. CO, assimilation and dissimilation in the light and dark in CAM plants, $p$. 217-234. In $\mathrm{CO}_{2}$ metabolism and plant productivity. University Park Press, Baltimore.

Perold, G.W., M.E.K. Rosenberg, A.S. Howard, and P.A. Huddle. 1979. Metabolites of Proteaceae. part9. Eximin (6- $O$-benzoylarbutin) and synthesis of aryl glycoside esters. J. Chem. Soc. Perkin I. p. 239-243.

Reid, M.S., W. vanDoorn, and J.P. Newman. 1991. Leaf blackening in protea. Acta Hort. 261:8184.

Robbins, N.S. and D.M. Pharr. 1988. Effect of restricted root growth on carbohydrate metabolism and whole plant growth of Cucumis sativus L. Plant Physiol. 87:409-413.

SAS Institute. 1987. SAS/STAT guide for Personal computers. version 6 ed. SAS Inst., Cary, N.C.

Smith, S.D. and P.S. Nobel. 1986. Deserts, p. 47-62. In: N.R. Baker and S.P. Long (eds.). Photosynthesis in contrasting environments. Elsevier Science Publishers, Amsterdam, The Netherlands.

Turgeon, R. 1989. The sink-source transition in leaves. Annu. Rev. Plant Physiol. Plant Mol. Biol. 40:119-138.

Whitehead, C.S. and G.H. de Swardt. 1982. Extraction and activity of polyphenoloxidase and peroxidase from senescing leaves of Protea neriifolia. S. African J. Bot. 1:127-130. 